\title{
Does Wearing High-heeled Shoe Cause Hallux Valgus? A Survey of 1,056 Chinese Females
}

\author{
by Daniel $\mathrm{Wu}, \mathrm{MD}^{1 \rrbracket}$, Lobo Louie, $\mathrm{DPE}^{2 凹}$
}

The Foot and Ankle Online Journal 3 (5): 3

Objective: To determine the prevalence of hallux valgus and its relationship to wearing high-heel shoes in Chinese females.

Methods: A total of 1,056 healthy females between the ages of 18 and 65 responded to the self-reported questionnaires. Photographs of each classified hallux valgus condition were given as references and each respondent was asked to rate her foot condition as well as completing a questionnaire. The study took place between June and August 2008 in Hong Kong.

Data analysis: Cross-tabulation and frequencies commands were used to compute the incidences of hallux valgus with regard to age, severity of illness, complaints and actions taken by the respondents. A chi-square statistic was used to compare the frequencies of occurrences between younger and older respondents. The relative risk $(R R)$ was calculated in order to understand the probability of having hallux valgus in relation to wearing high-heels and family history.

Results: Of the 1,056 respondents, 36.5\% indicated having various degree of hallux valgus. 29.5\% (n=312) had 'mild' condition, 4.8\% $(n=50)$ had 'moderate' and only 2.2\% $(n=24)$ reported 'severe' hallux valgus. No 'extreme' case was reported. Subjects over aged 40 had higher injury prevalence (chi-square $=34.4 ; p<.01$ ) than the young counterparts. $88.8 \%$ of those having hallux valgus reported that their family members had history of hallux valgus. $73.2 \%$ of them who did not wear high-heels regularly but with family history also had hallux valgus. For those with no family history but often wore high-heels, only $2.8 \%$ had hallux valgus. Subjects with family history of hallux valgus would be 26 times $(R R=26)$ as likely as those without family history and often wore high-heeled shoes to develop hallux valgus.

Conclusion: Hallux valgus is prevalent in the Chinese females. Wearing high-heels seemed to not be a predisposing factor of hallux valgus in Chinese females; however a family history was a major concern.

Key words: Hallux valgus, bunion, hallux abductovalgus, High-heeled shoe, Chinese females.

Accepted: April, 2010

Published: May, 2010

This is an Open Access article distributed under the terms of the Creative Commons Attribution License. It permits unrestricted use, distribution, and reproduction in any medium, provided the original work is properly cited. (The Foot and Ankle Online Journal (www.faoj.org)

$\mathrm{H}$ allux valgus is a chronic condition with deformity of the first metatarsophalangeal joint.

\footnotetext{
Address correspondence to: Stephen Hui Research Centre for Physical Recreation \& Wellness, Hong Kong Baptist University, Kowloon, Hong Kong. (852)3411-5631 Email: s62591@hkbu.edu.hk

${ }^{1}$ Department of Orthopaedics and Sports Injury, Hong Kong Adventist Hospital, Hong Kong. (852)2525-5035.

${ }^{2}$ Stephen Hui Research Centre for Physical Recreation \& Wellness, Hong Kong Baptist University, Kowloon, Hong Kong. (852)3411-5631.
}

It is characterized by lateral drift of the great toe in association with joint subluxation. The occurrence rates for hallux valgus varied depending on the age of the subjects involved. ${ }^{1}$

It was reported that the frequency rates of hallux valgus in the adult wearing population were about $33 \% .^{2}$ 

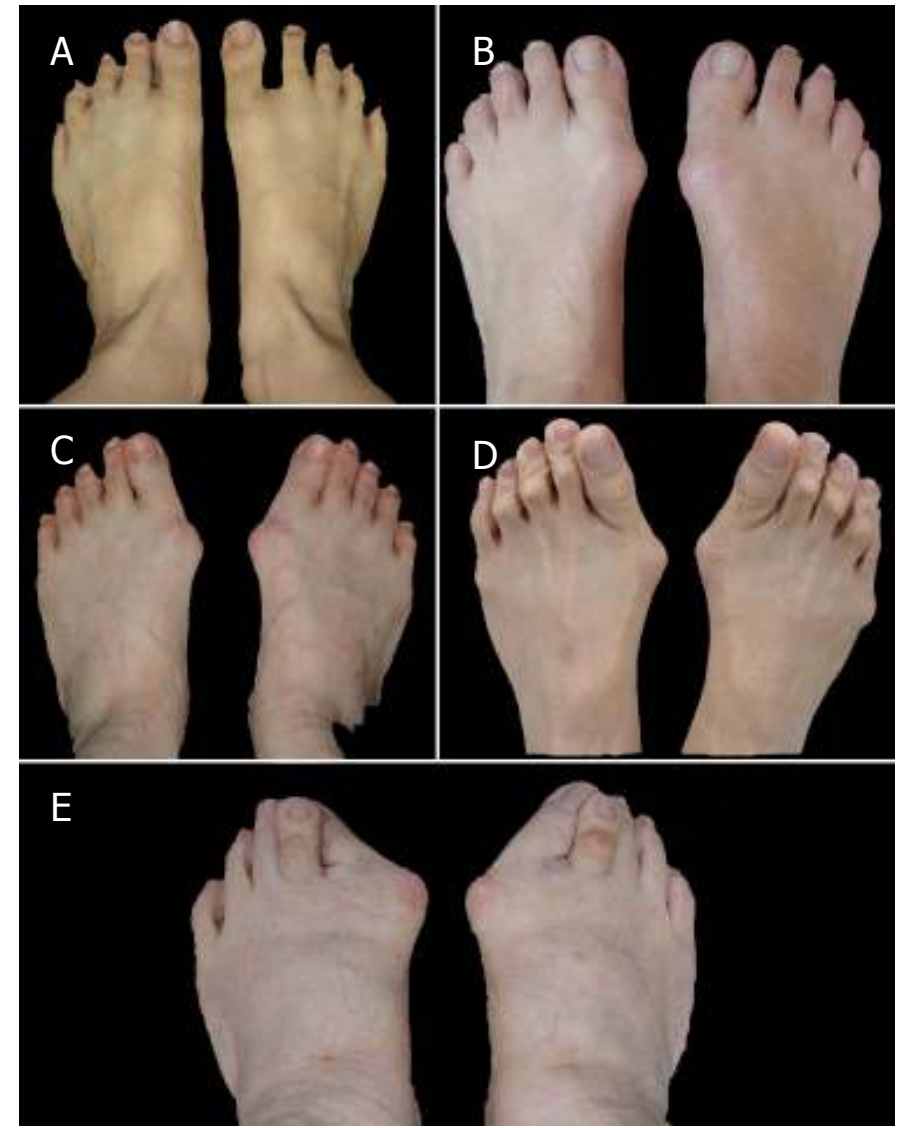

Figure 1 Self-rated hallux valgus conditions by the respondents. Characterized as normal foot $(A)$, mild bunion $(B)$, moderate bunion $(C)$, severe bunion $(D)$ and extreme bunion (E).

Another study indicated that the standardized prevalence of hallux valgus was $28.4 \%$ based upon a large sample of 4,249 respondents in a primary care population. $^{3}$ It was found that this deformity was associated with age, female sex, and components of generalized osteoarthritis, such as knee pain and big toe pain. However, hallux valgus was found as high as $64.7 \%$ in rural Korean women with age between 40 and 69 , but it did not significantly correlate with age. ${ }^{4}$

In a study done by Coughlin and Jones, ${ }^{5}$ they collected data from patients treated for a hallux valgus deformity and found that $83 \%$ of patients had a positive family history for hallux valgus deformities. Constricting shoes and occupation were implicated by $34 \%$ patients as a cause.
A recent study found that the prevalence of hallux valgus was associated with body mass index and highheel use during ages between 20 and $64 .^{6}$ They also reported that women, who wore regularly high-heeled shoes increased likelihood of hallux valgus. It is widely believed that dancers may put a great deal of stress through the first metatarsophalangeal joint which caused hallux valgus, but research did not support this assumption. ${ }^{7,8}$

Although the literature pertaining to the etiology of hallux valgus tends to be varied, there would appear predominantly on female population. The purpose of this study was to focus on evaluating the prevalence of hallux valgus and its relationship to wearing highheeled shoes in Chinese females.

\section{Methods}

A user-friendly self-report instrument containing photos of different degrees of hallux valgus were utilized (Fig. 1). Such classifications obtained high reliability and validity and this non-invasive method of assessing the severity of hallux valgus deformity was suggested for clinical and research purposes. ${ }^{9,10}$ In addition, data collected also included demographic information, wearing high-heeled shoes habit, family history, pain and symptoms, influence on daily life, diagnosis and treatment. Convenience sample method was used but the age of the respondents must be between 18 and 65 years. Questionnaires were delivered to the potential respondents in the community centers located in various districts in Hong Kong. In order to minimize the sample selection bias, the researcher distributed the questionnaires to the potential respondents in a random order. The researcher did not know whether the respondents had hallux valgus or not prior to distributing the questionnaires. Each respondent was asked to rate her own foot condition according to the given photos as well as filling out a questionnaire. The study took place between June and August 2008 in Hong Kong. Ethical approval was obtained. 


\begin{tabular}{lccc}
\hline Age (years) & $18-40$ & $41-65$ & Overall \\
\hline Normal & $65.8 \%$ & $58.6 \%$ & $63.5 \%$ \\
Mild bunions & $29.5 \%$ & $29.4 \%$ & $29.5 \%$ \\
Moderate bunions & $3.7 \%$ & $7.4 \%$ & $4.8 \%$ \\
Severe bunions & $1.1 \%$ & $4.6 \%$ & $2.2 \%$ \\
\hline
\end{tabular}

Table 1 Age difference in the prevalence of hallux valgus.

\section{Data Analysis}

Data were analyzed utilizing the Statistical Package for Social Sciences (SPSS version 16.0). Cross-tabulation technique was used to compute the incidences of hallux valgus between younger and older age groups, and across various severity of illness. In addition, frequencies command was employed to compute the descriptive statistics for the complaints and related actions taken by the respondents with hallux valgus. A chi-square statistic was utilized to compare the frequencies of occurrences between the younger (age 18-40 years) and older (age 41-65 years) groups. In an attempt to understand the probability of having hallux valgus in relation to family history and wearing highheels, the relative risk (RR) was calculated by dividing the number of hallux valgus cases who did not wear high-heels but with family history by those wore highheels with no family history. In order to facilitate data interpretation, percentage scores were utilized. Significance level was less than 0.05 .

\section{Results}

In total, 1,080 Chinese females responded to the survey. Twenty-four data entries were dropped due to incomplete information and thus 1,056 usable data were input for analysis (a return rate of 98.0\%). The demographic characteristics of the respondents indicated that they were from different socioeconomic backgrounds, including clerical workers $(29.7 \%)$, salespersons (4.4\%), flight attendants $(6.2 \%)$, service workers $(4.5 \%)$, teachers $(12 \%)$, discipline force $(6.8 \%)$, health care $(6.4 \%)$, and housewives $(30.1 \%)$.
Of the 1056 respondents, 36.5\% indicated having various degree of hallux valgus. It was reported that $29.5 \% \quad(n=312)$ had a 'mild' condition, 4.8\% $(n=50)$ had 'moderate' and only $2.2 \%(n=24)$ noted 'severe' hallux valgus. The findings also noted that $34.3 \%$ and $41.4 \%$ of the subjects with aged $18-40$ and $41-65$ years had hallux valgus, respectively. (Table 1) Respondents over aged 40 had significantly (chisquare $=34.4 ; \mathrm{p}<0.01$ ) higher injury prevalence than their young counterparts.

Of the total respondents, $226(21.4 \%)$ indicated that they always wore high-heeled shoes and 453 (42.9\%) sometimes wore them. The average year of wearing high-heels was 9.4 years (minimum $=0.5$ years; maximum $=38$ years). Similar average year (10.0 years) of wearing high-heels was also found in the hallux valgus group. Table 2 showed the frequent complaints reported by the respondents with hallux valgus. Some actions taken by the respondents with hallux valgus were presented in Table 3.

Eighty eight percent of respondents who had hallux valgus reported that their family members also had some forms of hallux valgus. However, it was found that $73.2 \%$ of them did not wear high-heels regularly but all had family history of hallux valgus. On the other hand, for those respondents without family history but often wore high heels, hallux valgus was found only in $2.8 \%$ of the total cases. It was estimated that subjects with family history of hallux valgus would be 26 times $(\mathrm{rr}=26)$ as likely as those without family history and often wore high-heeled shoes to develop hallux valgus. A summary showing the prevalence of hallux valgus between high- heels and family history was shown in Table 4. 


\begin{tabular}{lccc}
\hline Complaints & often & sometimes & never \\
\hline Feel tired in legs & $34 \%$ & $45 \%$ & $21 \%$ \\
Painful in injured area & $18 \%$ & $44 \%$ & $38 \%$ \\
Affect daily walking & $8 \%$ & $22 \%$ & $70 \%$ \\
Affect body balance & $6 \%$ & $18 \%$ & $76 \%$ \\
Affect daily work & $5 \%$ & $15 \%$ & $81 \%$ \\
\hline
\end{tabular}

Table 2 Frequent Complaints by the respondents with hallux valgus.

\begin{tabular}{lcc}
\hline Actions & yes & no \\
\hline Consult a doctor & $7 \%$ & $93 \%$ \\
Consult a physical therapy & $7 \%$ & $93 \%$ \\
Use an orthopedic device & $17 \%$ & $83 \%$ \\
Add a shoe pad & $39 \%$ & $61 \%$ \\
Wear wide toe box shoe & $57 \%$ & $43 \%$ \\
\hline
\end{tabular}

Table 3 Actions taken by the respondents with hallux valgus.

\begin{tabular}{llll}
\hline $\begin{array}{l}\text { Total respondents } \\
(n=1,056)\end{array}$ & Had hallux valgus & Wore high-heels & Did not wear high-heels \\
\hline Had hallux valgus $(n=385)$ & $100 \%$ & $18.4 \%$ & $81.6 \%$ \\
Had family history & $88.8 \%$ & $15.6 \%$ & $73.2 \%$ \\
No family history & $11.2 \%$ & $2.8 \%$ & $8.4 \%$ \\
\hline
\end{tabular}

Table 4 A summary showing the prevalence of hallux valgus between wearing high-heels and family history.

\section{Discussion}

Occurrence rates for hallux valgus reported in the literatures varied from $33 \%$ and $70 \%{ }^{2,11,12}$ The present finding $(36.5 \%)$ on the prevalence of hallux valgus in Chinese females was in line with previous data from other populations. ${ }^{4,6}$

Some people blame the causes of hallux valgus may be due to high heels. Wearing high-heels can be fashionable. Some people believe that high-heels can empower women at work and help women look and feel confident. Although wearing high-heels can cause several deleterious effects, such as putting too much force on the feet, ankles, knees, and lumbar, ${ }^{13,14,15}$ high-heels are welcome by women around the world. While wearing high-heels the feet are in plantarflexed position, which in turn significantly increases pressure on the plantar of the forefoot.
The pressure increases as the height of the shoe heel increases. Wearing a $31 / 4$ inch heel increases the pressure on the bottom of the forefoot by $76 \%$. The increased pressure may lead to pain or foot deformities.

Conversely, previous literature reviewed that constricting footwear was only found in about onequarter of the hallux valgus patients. ${ }^{16}$ In the present study, for those with no family history but often wore high-heels, only $2.8 \%$ of them developed hallux valgus. Apparently, the present finding did not agree with the cause of hallux valgus was due to wearing high-heels. Yet there is still insufficient evidence to conclude that wearing high-heeled shoe is an etiological factor in the development of hallux valgus. ${ }^{17}$ 
Almost $90 \%$ of respondents who had hallux valgus indicating that their family members also had some forms of hallux valgus. Such prevalence of hallux valgus was in line with the study conducted by Coughlin and Jones, ${ }^{5} 83 \%$ of hallux valgus patients had a positive family history. Recent study also showed that $90 \%$ of hallux valgus patients had at least one family member affected by the presence of hallux valgus and it might affect some family members across three generations. ${ }^{18}$ Interestingly, the present survey reported that a majority of the hallux valgus respondents $(73.2 \%)$ had family history of hallux valgus but they did not wear high-heels. This is exactly in line with Coughlin and Jones ${ }^{5}$ who reported that a positive family history is the underlying factor for hallux valgus deformities.

\section{Conclusion}

Hallux valgus is considered by many to be a prevalent condition in the females. This present study found that wearing high-heels is not a predisposing factor to hallux valgus. Instead, a family history appeared to be a major concern for developing hallux valgus in Chinese females.

\section{Disclosure}

No conflict of interest is reported by the authors.

\section{References}

1. Gilheany MF, Landorf KB, Robinson P. Hallux valgus and hallux rigidus: A comparison of impact on health-related quality of life in patients presenting to foot surgeons in Australia. J Foot Ankle Res 2008 1: 14.

2. Mann RR, Coughlin MJ. Adult hallux valgus. St Louis: Mosby 1993.

3. Roddy E, Zhang W, Doherty M. Prevalence and associations of hallux valgus in a primary care population. Arthritis Rheum 2008 59(6): 857-862.

4. Cho NH, Kim S, Kwon DJ, Kim HA. The prevalence of hallux valgus and its association with foot pain and function in a rural Korean community. JBJS 2009 91B (4): 494-498.

5. Coughlin MJ, Jones CP. Hallux valgus: demographics, etiology, and radiographic assessment. Foot Ankle Int 2007 28(7): 759-777.

6. Nguyen US, Hillstrom HJ, Li W, Dufour AB, Kiel DP, Procter-Gray E, Gagnon MM, Hannan MT. Factors associated with hallux valgus in a population-based study of older women and men: the MOBILIZE Boston study. Osteoarthritis Cartilage 2010 18(1): 41-46.

7. Kennedy JG, Collumbier JA. Bunions in dancers. Clin Sports Med. 2008 27(2): 321-328.

8. Einarsdóttir H, Troell S, Wykman A. Hallux valgus in ballet dancers: a myth? Foot Ankle Int. 1995 16(2): 92-94.

9. Roddy E, Zhang W, Doherty M. Validation of a self-report instrument for assessment of hallux valgus. Osteoarthritis and Cartilage 2007 15: 1008-1012.

10. Garrow AP, Papageorgiou A, Silman AJ, Thomas E, Jayson MI, Macfarlane GJ. The grading of hallux valgus: the Manchester scale. JAPMA 2001 91(2): 74-78.

11. Dawson J, Thorogood M, Marks SA, Juszczak E, Dodd C, Lavis G, Fitzpatrick R. The prevalence of foot problems in older women: a cause for concern. J Public Health Med 2002 24(2): $77-84$.

12. Menz HB, Lord SR. Gait instability in older people with hallux valgus. Foot Ankle Int 2005 26(6): 483-489.

13. Lee CM, Jeong EH, Freivalds A. Biomechanical effects of wearing high-heeled shoes. Int J Ind Ergo 2001 28: 321-326.

14. Mandato MG, Nester E. The effects of increasing heel height on forefoot peak pressure. JAPMA 1999 89(2): 75-80.

15. Kerrigan DC, Todd MK, Riley PO. Knee osteoarthritis and high-heeled shoes. Lancet 1998 351(9113): 1399-401.

16. Coughlin MJ. Juvenile hallux valgus: etiology and treatment. Foot Ankle Int 1995 16(11): 682-697.

17. Easley ME, Trnka HJ. Current concepts review: Hallux valgus part 1: pathomechanics, clinical assessment, and nonoperative management. Foot Ankle Int 2007 28(5): 654-659.

18. Piqué-Vidal C, Solé MT, Antich J. Hallux valgus inheritance: pedigree research in 350 patients with bunion deformity. J Foot Ankle Surg 2007 46(3): 149-154. 